\title{
Application of Experimental Design Technique to the Optimization of Bench-scale Composting Conditions of Municipal Raw Sludge
}

María Teresa Gea Leiva, Adriana Artola Casacuberta and Antoni Sánchez Ferrer*

Escola Universitària Politècnica del Medi Ambient

Rbla Pompeu Fabra 1

08100-Mollet del Vallès (Barcelona), Spain.

* Corresponding author: Antoni Sánchez Ferrer

Escola Universitària Politècnica del Medi Ambient. Rbla Pompeu Fabra 1, 08100-Mollet del Vallès (Barcelona), Spain.

Phone: 34-93-5796784

Fax: 34-93-5796785

E-mail address: asanchez@eupma.uab.es 


\begin{abstract}
Evaluation of the parameters affecting the compostability of dewatered raw sludge from a wastewater treatment plant has been carried out by means of a full factorial composite experimental design. The factors and their correspondent levels considered in the experimental design were: bulking agent:sludge ratio (from 1:1 to $4: 1$ by volume), bulking agent particle size (from 0-5 $\mathrm{mm}$ to $10-20 \mathrm{~mm}$ ) and composting volume (in the range of typical laboratory scale, from 1.5 to $25 \mathrm{~L}$ ).

Experimental design has permitted obtaining a polynomial second-order function that quantitatively describes the influence of the considered factors on the compostability of this waste in laboratory reactors. The function has been numerically optimized to find the optimal values for composting raw sludge resulting in a values of: $0-5 \mathrm{~mm}$ for bulking agent size, 1:1 for ratio bulking agent:sludge and a composting volume around $10 \mathrm{~L}$.

The use of this technique can be generalized and applied to the composting of other organic wastes and will permit the comparison of composting performance of different wastes.
\end{abstract}




\section{Introduction}

Handling and disposing of large quantities of sludge is a problem derived from the growing environmental awareness which is leading to an increasing number of wastewater treatment plants entering in operation (Lasaridi et al., 2000). The most extended disposal option adopted in European countries has been landfilling. At present, there is a tendency towards the agricultural use of sludge. The unique legal restriction to direct land application of the sludge is given by its content on heavy metals and potentially toxic compounds. European Union Commission is preparing a new Directive on the biological treatment of organic wastes (European Commission, 2001). According to this Directive the hygienisation of sludge before its application to land will be mandatory. Composting is one of the alternatives proposed by the Directive in order to achieve sludge hygienisation. The use of composting is not widespread in Europe, although trends are increasing.

The water content of sewage sludge is usually extremely high for direct composting even if a dewatering treatment is applied to this material. In a majority of cases a bulking agent is needed to reach optimum water content, porosity and free air space (FAS) (Haug, 1993). A lot of experiences are reflected in the literature referring the research of optimum sludge-bulking agent mixtures for urban or industrial sludge composting. A long list of waste materials have been proposed as bulking agents in these experiences including, among others, green waste (Sesay et al., 1997), wheat or barley straw (Lasaridi et al., 2000; Miner et al., 2001), rice husks (Morisaki et al., 1989) or peat moss (Milne et al., 1998), although the most widely used materials are wood chips and sawdust (Atkinson et al., 1996; Larsen and McCartney, 2000; Wong et al., 1997; Wong and Fang, 2000). In addition to the type of bulking agent used, its particle size has been also empathized as an important 
factor in sludge composting. Large bulking agent particles will provide an excess of FAS which will result in an oscillating temperature profile during composting (Jokela et al., 1997). The proportion of bulking agent in the final mixture has also been highlighted as a factor influencing the composting process (Morisaki et al., 1989; Jokela et al., 1997). Bulking agent:sludge volumetric ratios used in the reported experiences range from 0.5:1 to 6:1 depending mainly on the water content of the sludge (Wong et al., 1995; Larsen and McCartney, 2000). An excess of bulking agent will lead to a low content on biodegradable organic matter in the final mixture. Sludge composting experiences are presented in some cases at different scales, laboratory and pilot plant (Sesay et al., 1997; Jokela et al., 1997). The main difference observed at different scales is temperature evolution. The amount of heat generated and the heat retention capacity of the material increase as the volume of the treated material increases (Sherman-Hutton, 2000).

If the real influence of such a number of factors on sludge composting has to be statistically determined a detailed methodological study will be required including a large number of experiments.

The objective of this work is to examine the influence on relative heat generation (RHG) during raw sludge composting of the next three factors: bulking agent particle size, bulking agent:sludge volumetric ratio and operation volume (at laboratory scale). RHG is directly related to initial mixture water content because moisture determines the specific heat of the material (Haug, 1993). Nevertheless, since the selected factors for this study (bulking agent:sludge volumetric ratio and bulking agent particle size) determine water content, the effect of this parameter is implicit in the obtained results.

A full composite factorial experimental design technique has been used to plan the experiments needed. The experimental design technique will be used to learn on the 
influence of these factors on the sludge composting process and to determine the relationship among them. The variable studied is the integration of temperature curve as a measure of relative heat generation. The feasibility of the experimental design technique has been widely demonstrated in other fields (Lay et al., 1999; Sanchez et al., 2000a; Ricou-Hoeffer et al., 2001). Its application to the sludge composting process will provide a methodology to face future studies on the compostability of other types of organic waste.

\section{Materials and Methods}

\section{Materials}

The waste material under study was dewatered raw sludge from the urban wastewater treatment plant of La Garriga (Barcelona, Spain). The dewatered raw sludge was obtained by centrifugation of activated sludge from the biological wastewater treatment. Wood chips from a local carpentry were used as bulking agent. The chips consist of a variable mixture of pine and beech tree wood. The characteristics of these materials are presented in Table 1 (presented as average values during sampling time). The parameters summarized in Table 1 were determined according to standard procedures (APHA-AWWA-WPCF, 1992).

Sludge and wood chips mixtures were handmade after screening of the bulking agent. A semi-industrial sieve (Filtra Vibración, FT-400) with a diameter of $400 \mathrm{~mm}$ was used for wood chips screening. Three different screens (20, 10 and $5 \mathrm{~mm}$ mesh) were available. Initial mixtures water content ranged from $79.6 \%$ to $47.3 \%$. 


\section{Vessels}

Three different vessels were used in the reported experiments: a 40-L reactor (working volume: $25 \mathrm{~L}$ ) and 4.5-L and 1.5-L Dewar ${ }^{\circledR}$ vessels. A schematic representation of the $40-\mathrm{L}$ reactor is presented in figure 1 . The reactor is a cylindrical methacrylate tank with a perforated plate (at point 6) near the bottom that divides the vessel in two compartments. The upper compartment (A) over the perforate plate, contains the material to be composted while the empty compartment (B) under the perforated plate allows excess water content to leach providing at the same time an air distribution chamber when air supply is applied (air inlet at point 1). Leachate is recovered through a valve (2). The tank is top-covered with a methacrylate cover perforated in six points to allow exit of exhaust gas and monitoring of temperature (3) and oxygen concentration (4) in the tank. The vessel was thermo-insulated (5) with Cemiflex ${ }^{\circledR}$ foam (Cemiflex, Spain).

The Dewar vessels were conditioned for composting providing a stopper and placing a rigid wire net near the bottom to separate the material from a possible leachate. The stopper was perforated in two points for temperature monitoring and for air supply, if necessary.

Previously to the experiments with sludge, all vessels were validated for their use as composting tanks processing source-separated organic fraction of municipal solid waste (water content: $78 \%$, volatile solids content: $75 \%$ ), (Gea, 2001).

\section{Temperature Monitoring}

Pt-100 sensors were used for temperature monitoring connected to a data acquisition system (DAS-8000, Desin, Spain) which is connected to a standard PC. The system allows, by means of the proper software (Proasis ${ }^{\circledR}$ Das-Win 2.1, Desin, Spain), the continuos on- 
line visualization and registration of the value of different parameters (i.e. temperature and oxygen). Pt-100 sensors were placed in the material to have a measuring point at $1 / 3$ of the height of the material in the vessel.

\section{Oxygen Control}

Oxygen concentration in intersticial air was monitored with an oxygen sensor (Sensox, Sensotran, Spain). In Dewar vessels, oxygen control was carried out manually, whereas the 40-L reactor is equipped with a feedback oxygen control which automatically supplies fresh air to the reactor when oxygen concentration is below $10 \%$.

\section{Experimental Design}

Optimization of composting conditions was performed by means of a full composite factorial experimental design (Sánchez et al., 2000a; Sánchez et al., 2000b). Briefly, full factorial experimental design is based on the evaluation of the coefficients fitting a polynomial function $(\mathrm{Y})$, which is proposed to describe the system under study (see, for instance, Eq. 2 and 3). This polynomial function is an algebraic expression that combines the different factors $\left(\mathrm{x}_{\mathrm{i}}\right)$ that have been taken into account and their polynomial coefficients $\left(b_{i}\right)$. The factors considered were chosen according to the results obtained in previous experiments in sludge composting. Coefficients vector (B) of the function $\mathrm{Y}$ is calculated according to Eq. 1 (Trochim, 2002a; Trochim, 2002b):

$$
B=\left(M^{T} M\right)^{-1} M^{T} F_{o b j}
$$


where $\mathrm{M}$ is the matrix of experiments that includes the normalized levels of the considered factors, and $\mathrm{F}_{\mathrm{obj}}$ is the proposed objective function (in this case, relative heat generation). A number of experiments were replicated to validate statistically the consistence of the proposed function representing the system.

Calculation of Eq. 1 was carried out by a self-made software developed with Microsoft Fortran Powerstation® 4.0 (1994-1995).

Optimization of objective function was carried out by a quasi-Newton method using IMSL® libraries included in Microsoft Fortran Powerstation® 4.0 (1994-1995).

\section{Results}

\section{Previous Experiments}

Preliminary experiments (data not presented) showed that during dewatered raw sludge composting in static laboratory systems the thermophilic range of temperature was not always reached, even when the same bulking agent:sludge ratio used in composting fullscale plants was chosen. Moreover, Haug (1993) observed a clear influence of the bulking agent particle size and the operation scale, especially in cases when wet substrates (such as raw sludge) were used.

The problems detected can be overcome by means of a systematic and statistical study on the influence of these factors on the performance of composting of the waste under study. 


\section{Experimental Design}

The study of the factors affecting the composting process of dewatered raw sludge mixed with wood chips as bulking agent was carried out by means of a full composite factorial experimental design.

Bulking agent particle size, bulking agent:sludge volumetric ratio, and operation volume were selected as the main experimental factors that control the composting process. Bulking agent particle size and the bulking agent:sludge volumetric ratio directly determine Free Air Space (FAS) and water content (Haug, 1993), which are directly related to heat retention capacity. On the other hand, a high amount of total composting mass implies a large thermal inertia, and thus, a higher hygienization potential (Sherman-Hunton, 2000).

The levels of the factors considered in the experimental design are presented in Table 2. Wood chips were sieved to typical particle size values found in full-scale composting plants, whereas values of bulking agent:sludge volumetric ratio were selected among the typical referred values found elsewhere. The operation volumes were determined for the vessels available in the laboratory.

The considered factors and their respective levels involved the realization of 27 $(3 \times 3 \times 3)$ experiments, which were carried out following the evolution of temperature as a function of time in each case. Due to the high number of experiments, only the first thermophilic stage of the composting process was monitored, which in most cases corresponded approximately to 4 or 5 days. Experiments were carried out without air supply since it was previously observed that no oxygen limitation was found for any conditions tested in the experimental design (data not shown). To statistically validate the obtained results, 5 experiments were randomly chosen and carried out as replications to complete the experimental design, for a total of 32 experiments. 
Once the factors to be studied and their levels were chosen, the next step in the experimental design was the selection of an objective function $\left(\mathrm{F}_{\mathrm{obj}}\right)$. To evaluate the composting and hygienization potential of raw sludge:wood chips mixture, relative heat generation (RHG) based on the temperature achieved was chosen as the objective function. This parameter has been previously used in the composting field as a measure of composting potential (Larsen and McCartney, 2000; Leth et al., 2001). In this work, RHG was defined as the area between the reactor and room temperature curves, as shown in Figure 2. The RHG value was obtained by the Simpson integration method, considering the end point of the process when reactor temperature dropped to a value lower than $10^{\circ} \mathrm{C}$ over room temperature. Values of the objective function obtained for each experiment are presented in Table 3.

The next step in the experimental design was the election of a polynomial function (Y) that properly fitted the experimental results. This function was obtained to describe the process under study and it was used to check the influence of the factors on the composting process of raw sludge. The quality of the fitting for all the tested functions was estimated from the value of the correlation coefficient $\mathrm{R}^{2}$.

The simplest function proposed was a linear function considering all the factors studied and it is represented by Eq. 2:

$$
Y=b_{0}+\sum_{i=1}^{3} b_{i} x_{i}
$$

A low correlation coefficient, $\mathrm{R}^{2}=0.62$ was obtained in this case, which indicated a poor fitting of experimental data. In consequence, different new terms were included in the linear function (Eq. 2), to take into account possible interactions between the considered factors. The values of $\mathrm{R}^{2}$ showed that the best modelling function was a full second-order 
function including quadratic terms and interactions for $\mathrm{x}_{1}, \mathrm{x}_{2}$ and $\mathrm{x}_{3}$ (Eq. 3), where the value of $\mathrm{R}^{2}$ was 0.77 .

$$
Y=b_{0}+\sum_{i=1}^{3} b_{i} x_{i}+\sum_{i=4}^{6} b_{i} x_{i}^{2}+b_{7} x_{1} x_{2}+b_{8} x_{1} x_{3}+b_{9} x_{2} x_{3}
$$

The values of coefficients $b_{i}$ for Eq. 3 are presented in Table 4.

The quality of the fitting was statistically validated by means of an F-test. Experimental value of F-test was 8.10, higher than the tabulated value for a confidence of 99\%, which was 3.35. Thus, it could be assumed that the contributions of the factors were more significant than experimental error in the fitting of the statistical model. Therefore, a statistically validated function described by Eq. 3 could be used for the quantitative representation of the composting of raw sludge using wood chips as a bulking agent.

Moreover, analysis of $b_{i}$ coefficients (Table 4) indicated that the three factors under study affected the composting process in a similar order of magnitude. Also, the interaction between the variables was as significant as the variables themselves since the interactions affected the process in a similar order of magnitude. Analysis of the obtained function (Y) allows the study of the influence and interactions between the factors. For instance, for a fixed volume $\left(\mathrm{x}_{1}=0\right)$, Fig. 3 shows the combined influence of bulking agent particle size $\left(\mathrm{x}_{2}\right)$ and bulking agent:sludge volumetric ratio $\left(\mathrm{x}_{3}\right)$ on objective function.

The fact that the variables are interrelated is of especial relevance since the influence of these factors on composting performance is often considered separately or in the basis of adjusting a proper mixture water content or C:N ratio (Wong, et al., 1997; Milne et al., 1998; Kalyuzhnyi et al., 1999; Miner et al., 2001). However, this procedure does not ensure a correct Free Air Space value of the initial mixture. 


\section{Optimization}

Function $\mathrm{Y}$ obtained was used to determine the optimal conditions to carry out the composting process of a raw sludge:wood chips mixture under laboratory conditions, by means of an optimization program based on a quasi-Newton method. The results obtained were:

bulking agent particle size: $0-5 \mathrm{~mm}$

bulking agent:raw sludge ratio: 1:1

operation scale: $10.49 \mathrm{~L}$

The optimum mixture for the composting process carried out in laboratory scale vessels consisted of wood chips from 0 to $5 \mathrm{~mm}$, mixed in a 1:1 ratio with raw sludge. The small particle size produced a very homogeneous mixture with small sized aggregates, with a high porosity and more accessible to microorganisms and air, breaking the typical compacted structure of a dewatered sludge. This effect could be observed when mixing the materials for the experiments, and it was also reflected in partial results since maximum Relative Heat Generation values corresponded to the optimal mixture and the 2:1 ratio mixture in the three scale levels studied (Table 3). It is worthwhile to mention that the small sized wood chips can also act as amendment for raw sludge and not only as a bulking agent, since some carbon source is available for microorganisms and contributes to balance the excess of nitrogen often found in raw sludge (Haug, 1993).

The optimum value found for the operation volume indicated that the mixture $1: 1$ with 0-5 $\mathrm{mm}$ wood chips was suitable for laboratory scale operation when working with the studied materials. However, at full-scale operation, it seems evident that others factors such as compression, agitation, etc., can play an important role in the available Free Air Space (McCartney and Chen, 2001). 
The fact that the optimum value was near the lowest limit of the studied interval of volumes could be related to the different thermal insulation capacity of the used vessels. Thus, it seemed evident that the 1.5-L and 4.5-L Dewar vessels insulate the material and prevent heat loses in a more effective way than the 25 -L reactor. Although the three vessels had been previously validated composting source-separated organic fraction of municipal solid waste (MSW), reaching temperatures above $70^{\circ} \mathrm{C}$ for extended periods of time, the 25 $\mathrm{L}$ reactor did not have enough heat retention for materials such as raw sludge. Laboratory experiences show that biodegradation rate in the first stages of sludge composting process is lower than MSW, even with the same water content in the initial mixture.

Therefore, it can be concluded that composting of raw sludge at laboratory scale requires a proper thermal insulation.

Nevertheless, the optimization of the function obtained from the factorial experimental design has permitted the determination of the optimal conditions for the composting of raw sludge, proving to be a useful technique that can be applied to other similar wastes.

\section{Conclusions}

Composting process of raw sludge from urban wastewater treatment plant has been systematically studied, determining the factors affecting the compostability of this waste. In this work, it is of special interest the quantification of the influence of bulking agent:sludge ratio and the particle size of the added bulking agent.

Experimental design technique has proved to be a valid tool to determine the optimal initial operation conditions for the composting of raw sludge. Moreover, the systematic study of composting conditions by means of experimental design can be 
generalized and applied to the composting of other organic wastes and will permit the comparison of composting performance of different wastes.

\section{Acknowledgements}

The authors wish to thank the interest and help of Cesc Aguilera in the development of this work and the financial support of the Spanish Ministerio de Medio Ambiente (Project 2000/074).

\section{Nomenclature}

$b_{\mathrm{i}}$ : Coefficients of Y (B, coefficient vector).

FAS: Free Air Space.

M: Matrix of experiments.

MSW: Municipal Solid Waste.

$\mathrm{R}^{2}$ : Coefficient of correlation.

RHG: Relative Heat Generation.

$\mathrm{x}_{\mathrm{i}}$ : Independent variables of $\mathrm{Y}$.

Y: Modelling function obtained from experimental design.

$F_{\text {obj: }}$ Objective function. 


\section{References}

APHA-AWWA-WPCF. 1992. Standard Methods for the examination of water and wastewater. $18^{\text {th }}$ ed. American Public Health Association. Washington.

Atkinson, C.F., Jones, D.D. and Gauthier, J.J. 1996. Biodegradabilities and microbial activities during composting of oxidation ditch sludge. Compost Sci. Util., 4(1):8496.

European Commission. 2001. Working document. Biological treatment of biowaste. $2^{\text {nd }}$ draft. http://europa.eu.int/comm/environtment/waste/facts_en.htm.

Gea Leiva, M.T. 2001. Design and validation of bench-scale composting systems. Aplication to MSW and sludge treatment (original in Spanish). PhD Thesis, Universitat Autònoma de Barcelona.

Haug, R.T. 1993. The Practical Handbook of Compost Engineering. Lewis Publishers. Boca Raton, Florida.

Lay, J.J., Lee, Y.J. and Noike, T. 1999. Feasibility of biological hydrogen production from organic fraction of municipal solid waste. Wat. Res., 33(11):2579-2586.

Jokela, J., Rintala, J., Oikari, A., Reinikainen, O., Mutua, K. and Nyrönen, T. 1997. Aerobic composting and anaerobic digestión of pulp and paper mill sludges. Wat. Sci. Tech., 36(11):181-188.

Kalyuzhnyi, S., Sklyar, V., Federovich, V., Kovalev, A., Nozhevnikova, A., and Klapwijk, A. 1999. The development of biological methods for utilisation and treatment of diluted manure. Wat. Sci.Technol. 40(1):223-229. 
Larsen K.L. and McCartney, D.M. 2000. Effect of C:N ratio on microbial activity and N retention: bench-scale study using pulp and paper biosolids. Compost Sci. Util., 8(2):147-159.

Lasaridi, K.E., Stentiford, E.I. and Evans, T. 2000. Windrow composting of wastewater biosolids: process performance and product stability assessment. Wat. Sci. Tech., 42(9):217-226.

Leth, M., Jensen, H.E.K. and Iversen, J.J.L. 2001. Influence of different nitrogen sources on composting of Miscanthus in open and closed systems. Compost Sci. Util., 9(3):197-205.

McCartney, D. and Chen, H. 2001. Using a Biocell to measure effect of compressive settlement on Free Air Space and microbial activity in windrow composting. Compost Sci. Util., 9(4):285-302.

Milne, B.J., Baheri, H.R. and Hill, G.A. 1998. Composting of a heavy oil refinery sludge. Environ. Prog., 17(1):24-27.

Miner, F.D., Koeing, R.T. and Miller, B.E. 2001. The influence of bulking material type and volume on in-house composting in high-rise, caged layer facilities. Compost Sci. Util., 9(1):50-59.

Morisaki, N., Phae, C.H., Nakasaki, K., Shoda, M. and Kubota, H. Nitrogen transformation during thermophilic composting. J. Ferment. Bioeng., 67(1):57-61.

Ricou-Hoeffer, P., Lecuyer, I., and Le Cloirec, P. 2001. Experimental design methodology applied to adsorption of metallic ions onto fly ash. Wat. Res., 35(4):965-976.

Sánchez, A., Valero, F., Lafuente, J., and Solà, C. 2000a. Highly enantioselective esterification of racemic ibuprofen in a packed bed reactor using immobilised Rhizomucor miehei lipase. Enzyme Microb. Technol., 27:157-166. 
Sánchez, A., del Río, J.L., Valero, F., Lafuente, J., Faus, I. and Solà, C. 2000b. Continuous enantioselective esterification of trans-2-phenyl-1-cyclohexanol using a new Candida rugosa lipase in a packed bed bioreactor. J. Biotechnol., 84:1-12.

Sesay, A.A., Lasaridi, K., Stentiford, E. and Budd, T. 1997. Controlled composting of paper pulp sludge using the aerated static pile method. Compost Sci. Util., 5(1): $82-96$.

Sherman-Hutton, R. 2000. Latest developments in mit-to-large-scale vermicomposting. Biocycle, 41(11):51.

Trochim, B. 2002a. Factorial Designs. Research Methods Knowledge Base. http://trochim.human.cornell.edu/kb/expfact.htm. (18 Apr 2002).

Trochim, B. 2002b. Factorial Design Analysis. Research Methods Knowledge Base. http://trochim.human.cornell.edu/kb/statfact.htm. (18 Apr 2002).

Wong, J.W.C., Fang, M., Li, G.X. and Wong, M.H. 1997. Feasibility of using coal ash residues as co-composting materials for sewage sludge. Environ. Technol., 18:563568.

Wong, J.W.C. and Fang, M. 2000. Effects of lime addition on sewage sludge composting process. Wat. Res., 34(15):3691-3698.

Wong, J.W.C., Li, S.W.Y. and Wong, M.H. 1995. Coal fly ash as a composting maerial for sewage sludge: effects on microbial activities. Environ. Technol., 16:527-537. 


\section{Tables}

Table 1: Average properties of dewatered raw sludge and wood chips used in the experiments (in brackets, standard deviation values).

\begin{tabular}{lcc}
\hline Property & Dewatered Raw Sludge & Wood Chips \\
\hline Water Content (\%) & $73(5)$ & 5 \\
\hline Volatile Solids Content $(\%)$ & $60(4)$ & 99.4 \\
\hline N-Kjeldhal Content $(\%)$ & $2.5(0.4)$ & 0.1 \\
\hline C/N ratio & $13(3)$ & 500 \\
\hline
\end{tabular}


Table 2: Factors and levels considered in the experimental design (normalized values in parentheses).

\begin{tabular}{lccc}
\hline Factor & \multicolumn{3}{c}{ Levels } \\
\hline $\mathrm{x}_{1}:$ operation volume $(\mathrm{L})$ & $1.5(-1)$ & $4.5(-0.745)$ & $25(+1)$ \\
\hline $\mathrm{x}_{2}:$ bulking agent particle size $(\mathrm{mm})$ & $0-5(-1)$ & $5-10(-0.333)$ & $10-20(+1)$ \\
\hline $\mathrm{x}_{3}:$ bulking agent:sludge volumetric ratio & $1: 1(-1)$ & $2: 1(-0.333)$ & $4: 1(+1)$ \\
\hline
\end{tabular}


Table 3: Experimental results for the full factorial experimental design.

\begin{tabular}{|c|c|c|c|c|}
\hline Experiment & $\begin{array}{c}\text { Operation Volume } \\
x_{1}(\mathrm{~L})\end{array}$ & $\begin{array}{l}\text { Bulking agent particle size } \\
\qquad \mathbf{x}_{2}(\mathbf{m m})\end{array}$ & $\begin{array}{c}\text { Volumetric ratio } \\
\mathbf{x}_{3}\end{array}$ & $\begin{array}{c}\text { Objective function } \\
\left(\mathbf{F}_{\text {obj }}, \mathbf{R H G}\right)\end{array}$ \\
\hline $25 / 5 / 1: 1$ & 25 & $0-5$ & $1: 1$ & 78.29 \\
\hline $25 / 5 / 2: 1$ & 25 & $0-5$ & $2: 1$ & 17.29 \\
\hline $25 / 5 / 4: 1$ & 25 & $0-5$ & $4: 1$ & 13.66 \\
\hline $25 / 10 / 1: 1$ & 25 & $5-10$ & $1: 1$ & 33.26 \\
\hline $25 / 10 / 2: 1$ & 25 & $5-10$ & $2: 1$ & 22.87 \\
\hline $25 / 10 / 4: 1$ & 25 & $5-10$ & $4: 1$ & 0 \\
\hline $25 / 20 / 1: 1$ & 25 & $10-20$ & $1: 1$ & 27.80 \\
\hline $25 / 20 / 2: 1$ & 25 & $10-20$ & $2: 1$ & 2.88 \\
\hline $25 / 20 / 4: 1$ & 25 & $10-20$ & $4: 1$ & 0 \\
\hline $4.5 / 5 / 1: 1$ & 4.5 & $0-5$ & $1: 1$ & 124.07 \\
\hline 4.5/5/1:1-ii & 4.5 & $0-5$ & $1: 1$ & 100.99 \\
\hline $4.5 / 5 / 2: 1$ & 4.5 & $0-5$ & $2: 1$ & 152.18 \\
\hline $4.5 / 5 / 4: 1$ & 4.5 & $0-5$ & $4: 1$ & 16.25 \\
\hline $4.5 / 5 / 4: 1-\mathrm{ii}$ & 4.5 & $0-5$ & $4: 1$ & 70.77 \\
\hline $4.5 / 10 / 1: 1$ & 4.5 & $5-10$ & $1: 1$ & 136.93 \\
\hline $4.5 / 10 / 2: 1$ & 4.5 & $5-10$ & $2: 1$ & 24.30 \\
\hline 4.5/10/2:1-ii & 4.5 & $5-10$ & $2: 1$ & 39.12 \\
\hline $4.5 / 10 / 4: 1$ & 4.5 & $5-10$ & $4: 1$ & 10.51 \\
\hline 4.5/10/4:1-ii & 4.5 & $5-10$ & $4: 1$ & 15.46 \\
\hline $4.5 / 20 / 1: 1$ & 4.5 & $10-20$ & $1: 1$ & 36.24 \\
\hline $4.5 / 20 / 1: 1-\mathrm{ii}$ & 4.5 & $10-20$ & $1: 1$ & 28.70 \\
\hline $4.5 / 20 / 2: 1$ & 4.5 & $10-20$ & $2: 1$ & 11.17 \\
\hline $4.5 / 20 / 4: 1$ & 4.5 & $10-20$ & $4: 1$ & 5.58 \\
\hline $1.5 / 5 / 1: 1$ & 1.5 & $0-5$ & $1: 1$ & 86.27 \\
\hline $1.5 / 5 / 2: 1$ & 1.5 & $0-5$ & $2: 1$ & 87.32 \\
\hline $1.5 / 5 / 4: 1$ & 1.5 & $0-5$ & $4: 1$ & 16.25 \\
\hline $1.5 / 10 / 1: 1$ & 1.5 & $5-10$ & $1: 1$ & 63.91 \\
\hline $1.5 / 10 / 2: 1$ & 1.5 & $5-10$ & $2: 1$ & 25.09 \\
\hline $1.5 / 10 / 4: 1$ & 1.5 & $5-10$ & $4: 1$ & 0 \\
\hline $1.5 / 20 / 1: 1$ & 1.5 & $10-20$ & $1: 1$ & 32.83 \\
\hline $1.5 / 20 / 2: 1$ & 1.5 & $10-20$ & $2: 1$ & 20.68 \\
\hline $1.5 / 20 / 4: 1$ & 1.5 & $10-20$ & $4: 1$ & 0 \\
\hline
\end{tabular}


Table 4: Values of $b_{i}$ coefficients obtained for Eq. 3.

\begin{tabular}{lll}
\hline Coeficient & Coeficient for & Value \\
\hline $\mathrm{b}_{0}$ & - & 49.68 \\
\hline $\mathrm{b}_{1}$ & $\mathrm{x}_{1}$ & -5.963 \\
\hline $\mathrm{b}_{2}$ & $\mathrm{x}_{2}$ & -22.73 \\
\hline $\mathrm{b}_{3}$ & $\mathrm{x}_{3}$ & -24.67 \\
\hline $\mathrm{b}_{4}$ & $\mathrm{x}_{1}{ }^{2}$ & -43.56 \\
\hline $\mathrm{b}_{5}$ & $\mathrm{x}_{2}{ }^{2}$ & 17.00 \\
\hline $\mathrm{b}_{6}$ & $\mathrm{x}_{3}{ }^{2}$ & 8.353 \\
\hline $\mathrm{b}_{7}$ & $\mathrm{x}_{1} \cdot \mathrm{x}_{2}$ & 8.755 \\
\hline $\mathrm{b}_{8}$ & $\mathrm{x}_{1} \cdot \mathrm{x}_{3}$ & 5.745 \\
\hline $\mathrm{b}_{9}$ & $\mathrm{x}_{2} \cdot \mathrm{x}_{3}$ & 11.73 \\
\hline
\end{tabular}




\section{Legends to Figures}

Figure 1. Scheme of the 40-L vessel used in composting at laboratory scale. 1-Air inlet, 2Leachates outlet, 3-Temperature probe, 4-Air aspiration to oxygen sensor, 5-Thermal insulation, 6-Perforated plate, A-Composting volume, B-Leachates collection and air supply.

Figure 2. Evolution of temperature profiles for the experiment 1.5/5/2:1 (a) and 25/10/2:1 (b). ___ Material Temperature; .......... Room Temperature; Vertical line: End Point for the integration.

Figure 3. Surface response of Eq. 3 for a fixed normalized value of $X_{1}=0$. 
i 


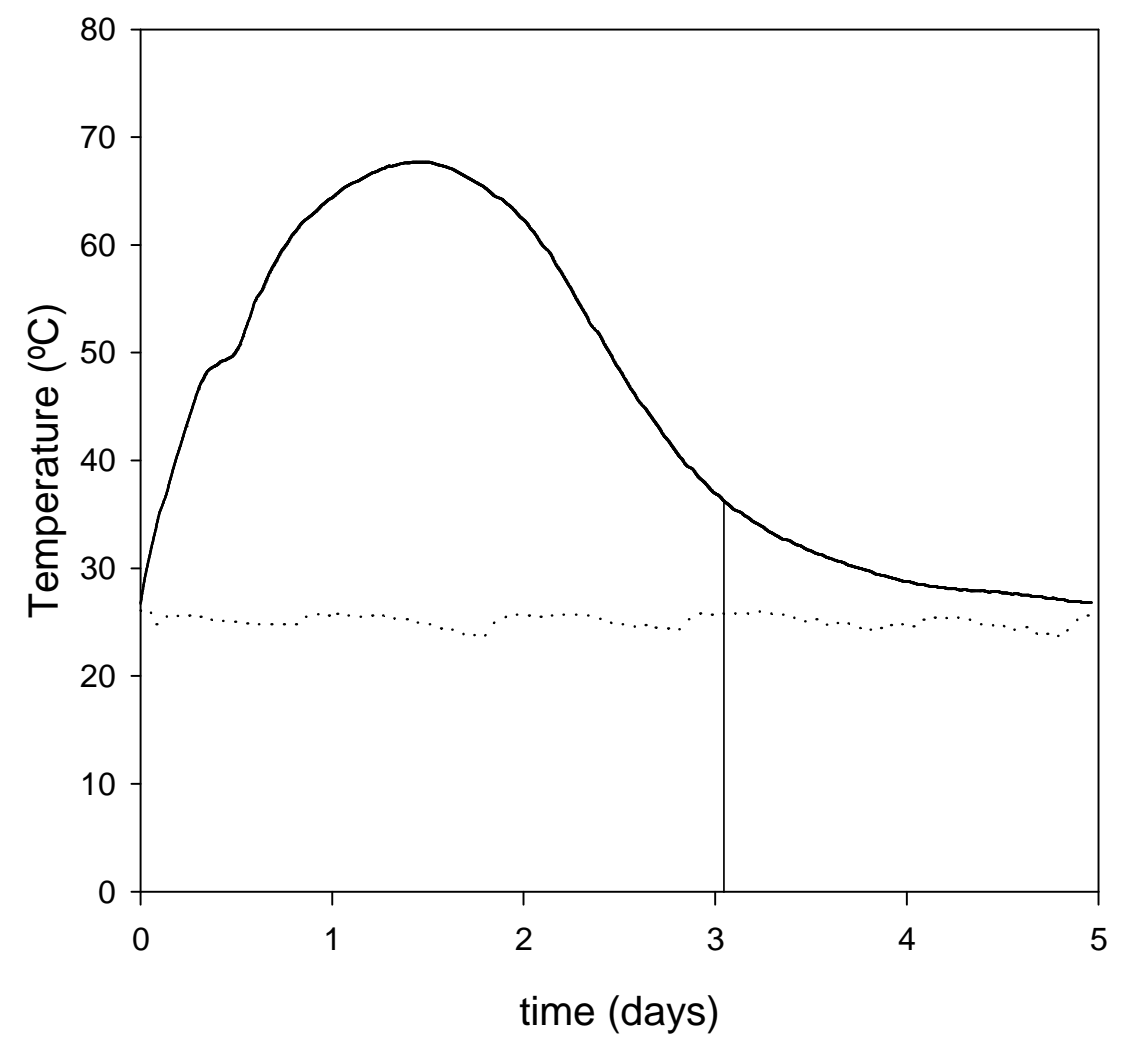




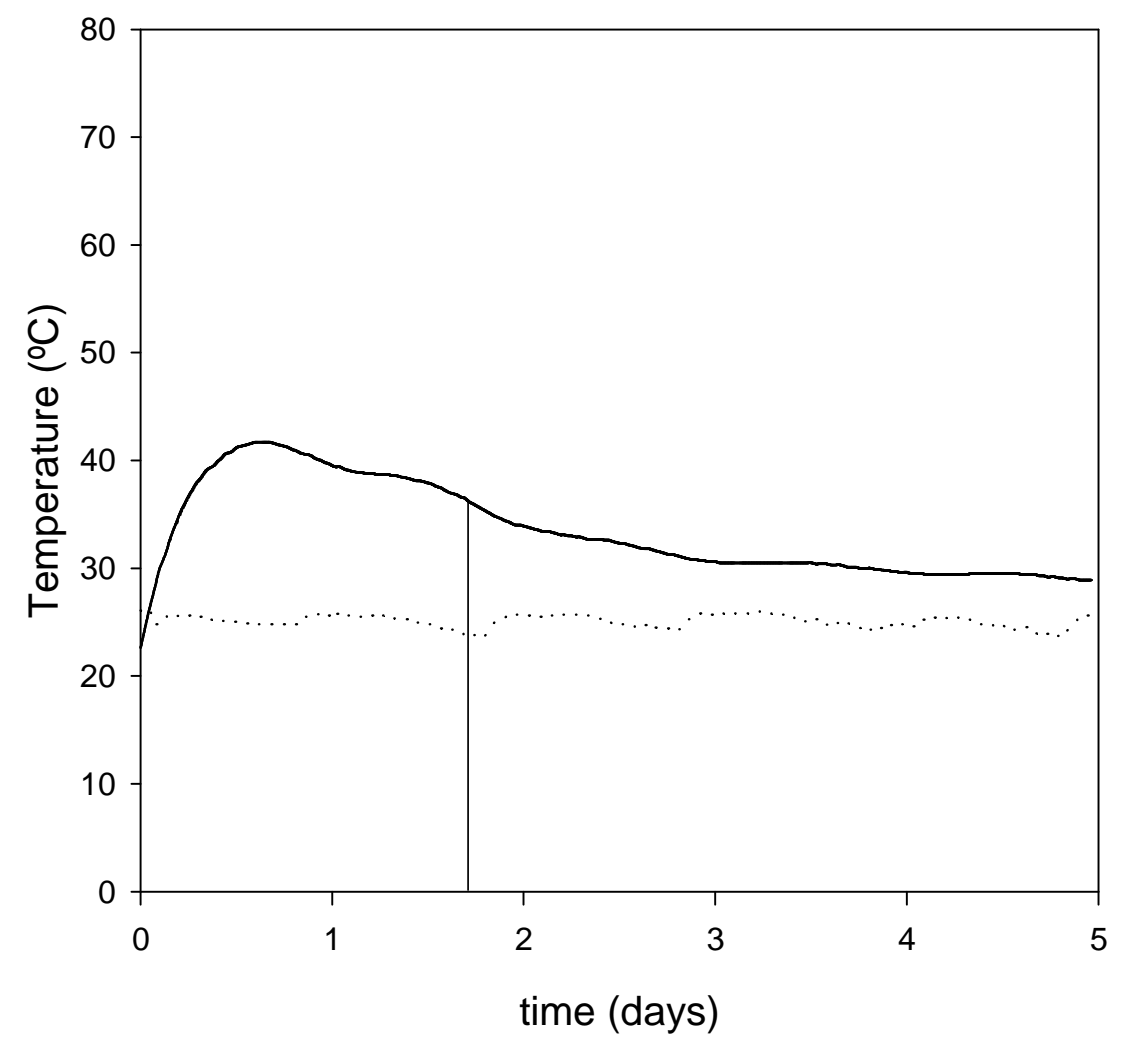




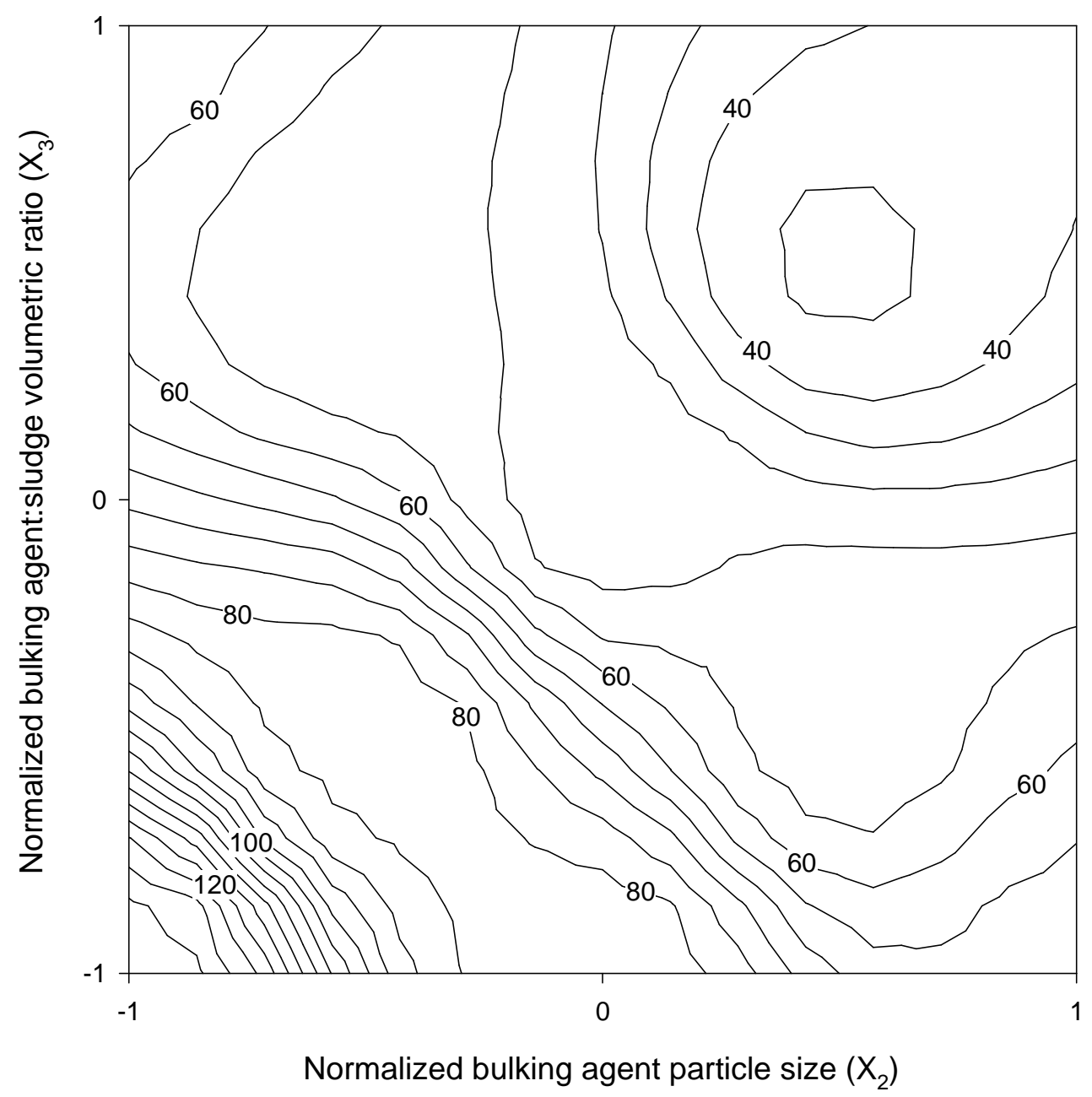

